\section{Duodenoscope Intubation of the Oesophagus in the Presence of Pharyngeal Pouch Made Possible by an Overtube}

Pharyngeal pouch may make intubation of the oesophagus with a duodenoscope as a preliminary to performing endoscopic retrograde cholangiopancreatography (ERCP) extremely difficult or impossible. and hazardous. The condition may be encountered as a cause of such difficulty when not previously diagnosed or elinically suspected.

We have encountered this problem in two (of over 1000 ) patients attending for ERCP. both of whom were elderly. Following failed intubation with the side-viewing duodenoscope. we performed endoscopy with an end-viewing instrument. intubating the oesophagus by the stecring method under direct vision, and thus establishing the basis of the difficulty. In the first case. even with this knowledge another attempt at intubation with the duodenoscope failed, and

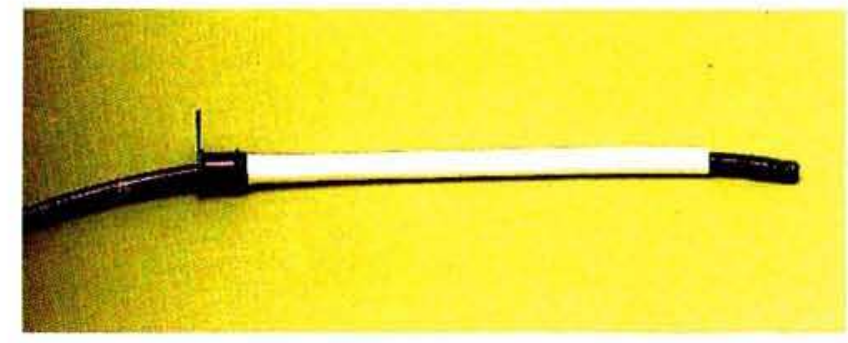

Figure 1: Duodenoscope COlympus Jf IT-10) within the KeyMed upper gastrontestual overtube.

the patient was referred for surgery. Encountering exactly the same problem in a recent patient with obstructive jaundice. we used an upper gastrointestinal overtube (Key Med. Southend-on-Sea. United Kingdom) to make intubation with the duodenoscope possible. 
The patient's oesophagus was intubated with an Olympus XQ-20 gastroscope, with the overtube held on the proximal portion of the patient insertion tube. The overtube was then gently passed into the upper oesophagus and the gastroscope removed. leaving the overtube in position. The duodenoscope (Olympus JF IT-10) was passed through its lumen into the upper gastrointestinal tract with ease, the overtube then being slid from the patient onto the proximal part of the insertion tube. where it remained during the rest of the procedure without causing significant impediment.

Our patient was found to have a neoplastic stricture requiring biliary stent placement. Since the overtube lumen diameter $(14 \mathrm{~mm})$ is not large enough to allow passage of the Olympus TJF type 10 stenting duodenoscope. the largest diameter stent that could be inserted was one of 7-Fr: we would normally use one of 12-Fr. An overtube of slightly larger internal diameter $(15 \mathrm{~mm})$ should be produced to allow passage of the larger stenting duodenoscopes when necessary in cases of pharyngeal pouch. All departments performing ERCP require such a device to make it possible to deal adequately with the needs of similar, albeit rare, cases.

W. Dickey, K. G. Porter

Department of Medicine, Belfast City Hospital and Queen's University of Belfast. Northern Ireland, United Kingdom

Corresponding tuthor

W. Dickey, M.D.

Department of Medicine

Queen's University of Belfast

Institute of Clinical Science

(irosvenor Road

Belfast BTI2 6B.J

United Kingdom 